\title{
Flavonoids as alpha-glucosidase inhibitors: mechanistic approaches merged with enzyme kinetics and molecular modelling
}

\author{
Didem Şöhretoğlu (iD) Suat Sari
}

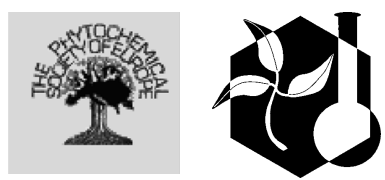

Received: 8 February 2019/Accepted: 21 May 2019/Published online: 25 May 2019

(C) Springer Nature B.V. 2019

\begin{abstract}
Diabetes mellitus is a major, global public health problem. $\alpha$-Glucosidase inhibitors are one of the most widely used classes of oral antidiabetics. In addition to other pharmaceutical benefits, flavonoids are known as potent $\alpha$-glucosidase inhibitors. In the last two decades, the latter property of flavonoids has attracted a great interest. In the current review, the literature on flavonoids as inhibitors of $\alpha$-glucosidase enzyme, their mechanism of action along with in silico studies and structure-activity relationships is discussed. The main outcomes show that a double bond between $\mathrm{C}-2$ and $\mathrm{C}-3$, and free hydroxyl groups at C-3 and $\mathrm{C}-4^{\prime}$ are crucial. Whereas sugar substitution at any position on the aglycon reduced the inhibitory effect, a phenolic group like gallic acid, coumaric acid, etc. substituted at different positions of sugar units increased it. Hydroxylation of flavonoids generally enhanced the effect due to possible electrostatic interactions with the enzyme, making flavonols stronger inhibitors than their flavone analogues. Hydroxyl groups at C-3, C-7, ring B, and the carbonyl oxygen at $\mathrm{C}-4$ are considered to be key modifications
\end{abstract}

D. Şöhretoğlu ( $\square)$

Department of Pharmacognosy, Faculty of Pharmacy, Hacettepe University, Sihhiye, 06100 Ankara, Turkey e-mail: didems@ hacettepe.edu.tr

S. Sari

Department of Pharmaceutical Chemistry, Faculty of Pharmacy, Hacettepe University, Sihhiye, 06100 Ankara, Turkey to enhance binding through hydrogen bonds. With this overview we intend to motivate and challenge researchers to design novel flavonoids a find new hits.

Keywords $\alpha$-Glucosidase Flavonol · Flavone · Isoflavone $\cdot$ Molecular docking

\section{Introduction}

Diabetes mellitus (DM), a chronic disease characterized by high blood glucose levels, stems from deficiencies in secretion of insulin, response to insulin, or both. Almost half a billion people have diabetes worldwide, and its prevalence is increasing continuously (IDF 2017). The chronic high blood glucose levels can cause severe complications, such as cardiovascular diseases, diabetic eye disease, nephropathy, diabetic foot, etc. Type $2 \mathrm{DM}$ is the most common form of DM, accounting for more than $90 \%$ of all the cases (IDF 2017). Insulin injection or oral antidiabetic drugs are used for its treatment. $\alpha$ Glucosidase inhibitors are one of the most widely-used classes of oral antidiabetics today. The enzyme $\alpha$ glucosidase, located in the brush border of the enterocytes of the jejunum, catalyzes hydrolysis of dietary carbohydrates and converts them into monosaccharides, which are then absorbed in jejunum. Thus, $\alpha$-glucosidase inhibitors delay glucose 
absorption and reduce postprandial blood glucose and insulin levels, hence alleviate hyperglycemia. Miglitol, acarbose, and voglibose are among the clinically used $\alpha$-glucosidase inhibitor drugs (Bischoff 1995; Krentz and Sinclair 2012; Lebovitz 1997). In spite of the variety of the available drugs, the response to and efficacy of the therapy is mainly dependent on the patients (Chaudhury et al. 2017). Thus, there is a tremendous interest to find novel and broad-spectrum antidiabetic agents.

It is well-known that dietary flavonoids play an important role for prevention of degenerative diseases. Furthermore, according to epidemiological studies, higher flavonoid consumption is associated with lower incidence of type $2 \mathrm{DM}$ (Xu et al. 2018, Yeon et al. 2015, Jacques et al. 2013; Liu et al. 2014). Apart from their preventative role, flavonoids are also effective for the treatment of diabetes (Pereira et al. 2011; Teoh and Das 2018; Ghorbani 2017). As the largest group of naturally occurring polyphenols, flavonoids are divided into several groups according the state of oxygenation of C-3. The main flavonoid subclasses are flavones, flavonols, flavanones, and isoflavones (Evans 2002) (Fig. 1). So far, numerous members of these groups have proved to be effective $\alpha$-glucosidase inhibitors in many studies (Proença et al. 2017, Söhretoglu et al. 2017, 2018a, b; Renda et al. 2018; Xiao et al. 2013). In this manuscript, we aimed to review recently published research articles that focus on $\alpha$-glucosidase inhibitor potential of flavones (Fig. 2), flavonols (Fig. 3), flavanones (Fig. 4), and
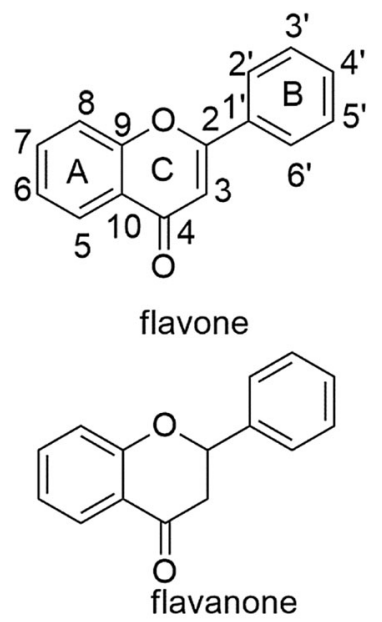<smiles>O=c1c(O)c(-c2ccccc2)oc2ccccc12</smiles>

flavonol<smiles>O=c1c(-c2ccccc2)coc2ccccc12</smiles>

isoflavone
Fig. 1 The main subclasses of flavonoids: flavones (1), flavonols (2), flavanones (3), isoflavones (4)<smiles>[R]c1ccc(-c2cc(=O)c3c([R3])c([R2])c([R])cc3o2)cc1[R]</smiles>

$\begin{array}{cccccc} & \mathrm{R}_{1} & \mathrm{R}_{2} & \mathrm{R}_{3} & \mathrm{R}_{4} & \mathrm{R}_{5} \\ \text { chrysin } & \mathrm{OH} & \mathrm{H} & \mathrm{OH} & \mathrm{H} & \mathrm{H} \\ \text { baicalein } & \mathrm{OH} & \mathrm{OH} & \mathrm{OH} & \mathrm{H} & \mathrm{H} \\ \text { apigenin } & \mathrm{OH} & \mathrm{H} & \mathrm{OH} & \mathrm{H} & \mathrm{OH} \\ \text { luteolin } & \mathrm{OH} & \mathrm{H} & \mathrm{OH} & \mathrm{OH} & \mathrm{OH} \\ \text { isovitexin } & \mathrm{OH} & \text { glucose } & \mathrm{OH} & \mathrm{H} & \mathrm{OH} \\ \text { isoorientin } & \mathrm{OH} & \text { glucose } & \mathrm{OH} & \mathrm{OH} & \mathrm{OH}\end{array}$

Fig. 2 Structures of selected flavones<smiles>[R]c1cc(-c2oc3cc(O)cc([R])c3c(=O)c2O)cc([R])c1[R]</smiles>

$\begin{array}{llllll} & \mathrm{R}_{1} & \mathrm{R}_{2} & \mathrm{R}_{3} & \mathrm{R}_{4} & \mathrm{R}_{5} \\ \text { galangin } & \mathrm{OH} & \mathrm{H} & \mathrm{H} & \mathrm{H} & \mathrm{H} \\ \text { fisetin } & \mathrm{H} & \mathrm{H} & \mathrm{H} & \mathrm{OH} & \mathrm{OH} \\ \text { kaempferol } & \mathrm{OH} & \mathrm{H} & \mathrm{H} & \mathrm{OH} & \mathrm{H} \\ \text { quercetin } & \mathrm{OH} & \mathrm{H} & \mathrm{OH} & \mathrm{OH} & \mathrm{H} \\ \text { morin } & \mathrm{OH} & \mathrm{OH} & \mathrm{H} & \mathrm{OH} & \mathrm{H} \\ \text { myricetin } & \mathrm{OH} & \mathrm{H} & \mathrm{OH} & \mathrm{OH} & \mathrm{OH}\end{array}$

Fig. 3 Structures of selected flavonols

isoflavones (Fig. 5) including those which feature in silico approaches to give an overview on the structure activity-relationships (SARs) as well as the molecular determinants of inhibition mechanisms of this class of compounds. Since review articles covering proceedings up to early 2010 s on this field are already available, we mainly focused on the findings published in the last decade.

For the biological studies, Saccharomyces cerevisiae $\alpha$-glucosidase was the most widely used source for a-glucosidase except for only a couple of different sources, such as Bacillus stearothermophilus or rat intestinal $\alpha$-glucosidase. Therefore we referred to Saccharomyces cerevisiae $\alpha$-glucosidase simply as " $\alpha$-glucosidase" and mention the source organism names other than Saccharomyces cerevisiae 
Fig. 4 Structures of selected flavanones

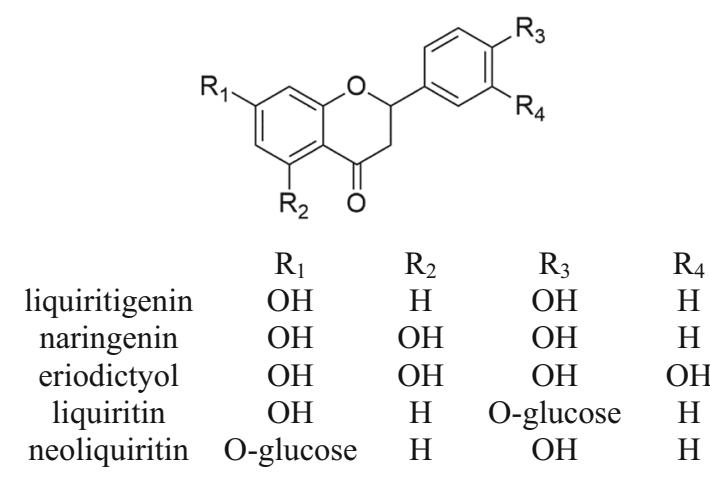

$\begin{array}{ccccc} & \mathrm{R}_{1} & \mathrm{R}_{2} & \mathrm{R}_{3} & \mathrm{R}_{4} \\ \text { liquiritigenin } & \mathrm{OH} & \mathrm{H} & \mathrm{OH} & \mathrm{H} \\ \text { naringenin } & \mathrm{OH} & \mathrm{OH} & \mathrm{OH} & \mathrm{H} \\ \text { eriodictyol } & \mathrm{OH} & \mathrm{OH} & \mathrm{OH} & \mathrm{OH} \\ \text { liquiritin } & \mathrm{OH} & \mathrm{H} & \text { O-glucose } & \mathrm{H} \\ \text { neoliquiritin } & \text { O-glucose } & \mathrm{H} & \mathrm{OH} & \mathrm{H}\end{array}$<smiles>C=C(C)[C@H](CC=C(C)C)Cc1c(O)c(CC=C(C)C)c(O)c2c1OC(c1ccc(O)cc1O)CC2=O</smiles>

Kushenol B<smiles>CC(C)=CCc1c(O)c(CC=C(C)C)c2c(c1O)C(=O)CC(c1ccc(O)cc1O)O2</smiles>

Kushenol E<smiles>[R]c1cc([R2])c2c(=O)c(-c3ccc(O)cc3)coc2c1</smiles><smiles>CC1(C)C=Cc2cc3c(=O)c(-c4ccc(O)cc4)coc3cc2O1</smiles>

alpinumisoflavone

$$
\begin{array}{lll} 
& \mathrm{R}_{1} & \mathrm{R}_{2} \\
\text { daidzein } & \mathrm{OH} & \mathrm{H} \\
\text { genistein } & \mathrm{OH} & \mathrm{OH} \\
\text { prunetin } & \mathrm{OCH}_{3} & \mathrm{OH}
\end{array}
$$

Fig. 5 Structures of selected isoflavonoids

throughout the manuscript, which is organized to group the SARs according to the rings of the general flavonoid structure (ring A, B, and C) and subgroup each ring into the flavonoid subclasses.

Flavonoids are benzo- $\gamma$-pyrone derivatives containing a C-6-C-3 unit formed from shikimic acid pathway and a second C-6 unit generated by polyketide pathway. They consist of two aromatic rings (A and $\mathrm{B}$ ) linked via a $4 \mathrm{H}$-pyran ring (C) and classified according to the oxygenation state and unsaturation of the C-3 unit. The main flavonoid subclasses are flavones, flavonols, flavanones, and isoflavones. Naturally occurring flavonoids are present as agylcones or glycosides. The most common flavonoid glycosides are $O$-glycosides, however considerable number of them occur as $C$-glycosides. Flavonoids are present in pretty much all plant species, but the subgroups (flavones, flavonols, isoflavones, etc.) are limited to fewer species. Flavones are 2-phenylchromen-4-one derivatives, including apigenin and luteolin. Flavonols share 3-hydroxy-2-phenylchromen-4-one scaffold with the most common members being quercetin, kaempferol, myricetin, and their derivatives. Due to a carbonyl group at C-4 and a hydroxyl group at C-3 of ring $C$, they seem to be the most powerful $\alpha$ glycosidase inhibitory flavonoid subgroup. Flavanones have 2,3-dihydro-2-phenylchromen-4-one backbone. Naringenin, and eriodictyol are among the well-known flavanones. Isoflavones are 3-phenylchromen-4-one derivatives, such as genistein, and daidzein. In addition to their well-known phytoestrogen properties, they are also potent $\alpha$-glycosidase inhibitor compounds.

\section{Methods used to evaluate the $\alpha$-glucosidase inhibitory effects of flavonoids}

The most common assays to evaluate the in vitro $\alpha$ glucosidase inhibitory effects of flavonoids is a spectrometric method based on measuring the release of yellow-colored $p$-nitrophenol from $p$-nitrophenyl$\alpha$-D-glucopyranoside. In most of the papers we reviewed, Saccharomyces cerevisiae $\alpha$-glucosidase was the enzyme used for in vitro studies (Şöhretoğlu et al. 2017; Costa et al. 2015; Fu et al. 2018). Bacillus 
stearothermophilus and rat small intestine were among the other sources of $\alpha$-glucosidase (Chang et al. 2015; Flores-Bocanegra et al. 2015). In this method, the activity of enzyme is determined by monitoring the conversion of the colourless substrate to the product, ( $p$-nitrophenyl- $\alpha$-glucopyranoside to $p$ nitrophenyl) (dissolved in phosphate buffer $\mathrm{pH} 6.8$ or 6.9) into a product that can be detected spectrophotometrically at $405 \mathrm{~nm}$. Any potential inhibitors (test compounds or positive control) are prepared in DMSO, methanol, water or in mixtures with water or phosphate buffer and then added to the reaction mixture. In some studies the three reactants (enzyme, inhibitor and substrate) were incubated at 25 or $37{ }^{\circ} \mathrm{C}$ for $20-45 \mathrm{~min}$ and the absorbance was monitored during this time course (Costa et al. 2015; Fu et al. 2018). However, in some studies, researchers preincubated the enzyme and the inhibitors at 25 or $30^{\circ} \mathrm{C}$ for 15-60 min before the addition of the substrate (Proença et al. 2017; Şöhretoğlu et al. 2017; Zhang et al. 2015). In this case, the test samples were also incubated at 25 or $37{ }^{\circ} \mathrm{C}$ for 10 or 30 min following the addition of the substrate. After adding $\mathrm{Na}_{2} \mathrm{CO}_{3}$ to finalize reaction, absorbance is read at 405 or $415 \mathrm{~nm}$. The percentage inhibition (\%) is calculated using the following equation:

$$
\begin{aligned}
& \text { inhibition }(\%)=\left[1-\left(\mathrm{A}_{\text {control }}-\mathrm{A}_{\text {sample }}\right) /\left(\mathrm{A}_{\text {control }}\right)\right] \\
& \quad \times 100,
\end{aligned}
$$

in which $\mathrm{A}_{\text {control }}$ is the activity of the enzyme without compound/extract/reference and $\mathrm{A}_{\text {sample }}$ is the activity of the enzyme with compound/extract/reference at different concentrations. Acarbose was used as positive control except Zhang et al., who used genistein as positive control (Costa et al. 2015; Proença et al. 2017; Şöhretoğlu et al. 2017; Zhang et al. 2015). In one of the studies where rat intestinal $\alpha$-glucosidase was used, the enzyme was extracted from rat intestinal acetone powder, which had been homogenized using ice-cold phosphate buffer ( $\mathrm{pH}$ 7.4). After sonicating for ten minutes, the content was centrifuged at $6400 \mathrm{rpm}$ for $10 \mathrm{~min}$. The supernatant was recovered and used for the assay. After isolation of the enzyme, the standard procedures were applied as defined above (Flores-Bocanegra et al. 2015).

\section{Flavonoids as alpha glucosidase inhibitors}

\section{Ring A}

\section{Flavones}

In a comprehensive study where flavonoids of diverse subclasses were evaluated, baicalein inhibited $\alpha$ glucosidase with an $\mathrm{IC}_{50}$ value of $44 \mu \mathrm{M}$, whereas $\mathrm{IC}_{50}$ value of chrysin was higher than $200 \mu \mathrm{M}$, suggesting that 5-hydroxy substitution enhanced the inhibitory effect (Proença et al. 2017). Chang et al. studied the effects of apigenin 7-O- $\beta$-glucoside and its acylated derivatives on Bacillus stearothermophilus $\alpha$-glucosidase. $\mathrm{IC}_{50}$ value of apigenin 7- $O$ - $\beta$-glucoside was higher than the range of concentrations tested (higher than $200 \mu \mathrm{M}$ ) but its derivatives proved potent inhibitors. These derivatives, including apigenin 7-O$\left(6^{\prime \prime}\right.$ - $(E)$-ferulate)- $\beta$-glucoside $(8.8 \mu \mathrm{M})$, apigenin 7- $O$-(6" 6 - $(E)$-p-coumarate)- $\beta$-glucoside $\quad(14.6 \mu \mathrm{M})$, apigenin $\quad 7-O-\left(6^{\prime \prime} \%-(Z)\right.$-p-coumarate)- $\beta$-glucoside $(10.1 \mu \mathrm{M})$, and apigenin $7-O-\left(6^{\prime \prime} \%-(E)\right.$-cinnamate $)-\beta$ glucoside $(11.3 \mu \mathrm{M})$ exhibited similar inhibitory effects. The authors concluded that hydroxy or methoxy substitutions on the phenyl group and the geometric isomerism in the phenylpropenoyl moiety did not play important role in enzyme inhibition (Chang et al. 2015). In a study by Li et al., the $\alpha$ glucosidase inhibitory effects $\left(\mathrm{IC}_{50}\right)$ of luteolin and its 8- $C$-glucoside, orientin, 6- $C$-glucoside, isoorientin; apigenin, and its 8-C-glucoside, vitexin, and $6-C$ glucoside, isovitexin were found as 13.07, 23.30, $19.68,21.85,25.11$, and $23.26 \mu \mathrm{g} / \mathrm{mL}$, respectively. These results indicated that glycosylation at C-6 or C-8 in ring A of flavones decreases the inhibitory activity. The C-6 glycosylation reduced the effect slightly less than the $\mathrm{C}-8$ glycosylation ( $\mathrm{Li}$ et al. 2009a).

In another study, the $\mathrm{IC}_{50}$ values of isovitexin, apigenin-6- $C$ - $\alpha$-L-rhamnopyranosyl- $(1 \rightarrow 2)-\left(6^{\prime \prime}-O\right.$ acetyl)- $\beta$-D-glucopyranoside, isoorientin, luteolin-6$C$ - $\alpha$-L-rhamnopyranosyl-( $1 \rightarrow 2)-\left(6^{\prime \prime}-O\right.$-acetyl)- $\beta$-Dglucopyranoside, isovitexin- $2^{\prime \prime}-O$-rhamnoside, isoorientin- $2^{\prime \prime}$ - $O$-rhamnoside were found as $32,19,29,25$, 35 , and $34 \mu \mathrm{M}$, respectively. All these compounds exhibited weaker effect than the positive control, acarbose, however 6 " acetylation reportedly improved the effect (Costa et al. 2015). 


\section{Flavonols}

In one study, the $\mathrm{IC}_{50}$ values of quercetin and fisetin were reported as 7 and $13 \mu \mathrm{M}$ respectively, suggesting that 5-hydroxy substitution enhanced the inhibitory potential of flavonols, too (Tadera et al. 2006). In another study featuring quercetin and its derivatives, the $\mathrm{IC}_{50}$ values of 8-prenyl-quercetin, 8-geranylquercetin, quercetin, and acarbose were found as $4.38,1.15,10.98$, and $50 \mu \mathrm{M}$, respectively. These results suggested that both geranyl and prenyl substitutions at C-8 position of ring A enhanced inhibitory potential. Furthermore, geranylation enhanced the inhibitory potential more than prenylation did (Sun et al. 2015).

\section{Flavanones}

In their study, Gou et al. investigated $\alpha$-glucosidase inhibitory potentials of liquiritigenin and neoliquiritin (liquiritigenin-7-O-glucopyranoside) and determined their $\mathrm{IC}_{50}$ values as 3.36 and $31.30 \mu \mathrm{g} / \mathrm{mL}$, respectively, which were lower than that of acarbose $(38.99 \mu \mathrm{g} / \mathrm{mL})$. These results showed a reduced activity upon sugar substitution to C-7, as well as $O$ glycosylation, in ring A (Gou et al. 2016). In a study investigated $\alpha$-glucosidase inhibitory potential of lavandulyl flavanones, the $\mathrm{IC}_{50}$ values of kushenol $\mathrm{B}, \mathrm{E}$, and acarbose were found as 24.6, 11.0, and $119.2 \mu \mathrm{M}$, respectively, suggesting that replacement of 8-prenyl by lavandulyl group enhanced the inhibitory effect. Kushenol E and B reportedly inhibited $\alpha$-glucosidase in an un-competitive manner (Kim et al. 2017).

\section{Isoflavones}

Hydroxylation at $\mathrm{C}-5$ of the ring $\mathrm{A}$ of daidzein $\left(\mathrm{IC}_{50}\right.$ : $14 \mu \mathrm{M})$ to genistein $\left(\mathrm{IC}_{50}: 7 \mu \mathrm{M}\right)$ reportedly improved the inhibitory potential of isoflavonoids, too (Tadera et al. 2006). In a recent study by Şöhretoğlu et al., the $\mathrm{IC}_{50}$ values of prunetin-5-O- $\beta$-glucopynoside, genistein-5-O- $\beta$-glucopynoside, prunetin, and genistein were $56.05,43.24,31.87$, and $1.47 \mu \mathrm{g} / \mathrm{mL}$, whereas the $\mathrm{IC}_{50}$ of acarbose was $31.92 \mu \mathrm{g} / \mathrm{mL}$. Prunetin-5-O$\beta$-glucopynoside and genistein were uncompetitive, genistein 5-O- $\beta$-glucopyranoside was competitive, and prunetin was noncompetitive inhibitor of the enzyme. These results suggested that sugar substitution to 5-hydroxyl group reduced the inhibitory potential. It also showed that $O$-glycosylation in A ring reduced the effect (Şöhretoğlu et al. 2017). In a study conducted on isoflavonoids, geranyl substitution to C-8 of genistein increased inhibitory effect approximately 8-fold, however, prenyl substitution to the same position decreased the effect dramatically. Moreover, methyl substitution to C-7 or C-5 and C-7 of 8-geranyl-genistein also weakened the inhibitory effect (Sun et al. 2015).

\section{Ring B}

\section{Flavones}

In a study that investigated $\alpha$-glucosidase inhibitory effects of a set of flavonoids, the $\mathrm{IC}_{50}$ values of flavone, 3'-hydroxyflavone flavone, and 4'-hydroxyflavone flavone could not be determined even at $200 \mu \mathrm{M}$. But $3^{\prime}, 4^{\prime}$-dihydroxyflavone inhibited $\alpha$-glucosidase $32 \%$ at $200 \mu \mathrm{M}$. In the same study, the $\mathrm{IC}_{50}$ values of apigenin, luteolin, and 5,7,3'-trihdroxyflavone were found as 82,46 , and $89 \mu \mathrm{M}$, respectively. These results suggested that, $3^{\prime}, 4^{\prime}$-dihydroxy substitution increased the activity compared to one hydroxyl substitution at either $3^{\prime}$ or $4^{\prime}$ position of the flavone ring B. (Proença et al. 2017). Contrary to these findings, Zhen et al. found that an extra hydroxyl group at $3^{\prime}$ decreased the effect. Moreover, they highlighted the importance of $4^{\prime}$-hydroxyl of flavone ring B (Zhen et al. 2017). In a study aimed to investigate the effects of certain substitutions to ring B on $\alpha$-glucosidase enzyme, the effects of these substitutions were found to be parallel to the effects of baicalein. $3^{\prime}, 4^{\prime}$-Dihydroxyflavone exhibited the highest inhibitory effect compared to $2^{\prime}$-, $3^{\prime}$-, $4^{\prime}$-hydroxy, or $2^{\prime}, 3^{\prime}, 4^{\prime}$-trihydroxyflavone. Flavones with a $2^{\prime}$ - or a $3^{\prime}$-hydroxy substitution alone exhibited the lowest effect. They suggested that $4^{\prime}$-hydroxy substitution was important but extra hydroxyl groups were not always advantageous (Gao and Kawabata 2004). In another study, the $\mathrm{IC}_{50}$ values of isovitexin, apigenin-6$C$ - $\alpha$-L-rhamnopyranosyl- $(1 \rightarrow 2)-\left(6^{\prime \prime}-O\right.$-acetyl $)-\beta$-Dglucopyranoside, isoorientin, luteolin-6- $C$ - $\alpha$-L-rhamnopyranosyl- $(1 \rightarrow 2)-\left(6^{\prime \prime}-O\right.$-acetyl)- $\beta$-D-glucopyranoside, isovitexin- $2^{\prime \prime}-O$-rhamnoside, and isoorientin- $2^{\prime \prime}-O$ rhamnoside were found as 32,19, 29, 25, 35, and $34 \mu \mathrm{M}$, respectively. All these compounds exhibited weaker effects than acarbose. According to these results 
3 -hydroxy substitution weakened or did not change the effect (Costa et al. 2015). Chang et al. investigated inhibitory effects of a set of flavones having either luteolin or apigenin skeleton on Bacillus stearothermophilus $\alpha$-glucosidase. Among them, isovitexin $2^{\prime \prime}$ (E)-p-coumarate displayed the best inhibitory activity with an $\mathrm{IC}_{50}$ value of $4.3 \mu \mathrm{M}$, however the $\mathrm{IC}_{50}$ of acarbose was $0.033 \mu \mathrm{M}$. Isoorientin $2^{\prime \prime}-(E)-p$-coumarate exhibited weaker activity compared to isovitexin $2^{\prime \prime}-(E)$-p-coumarate $\left(\mathrm{IC}_{50}=35.7 \mu \mathrm{M}\right)$, suggesting that additional hydroxyl group at the $\mathrm{C}-3^{\prime}$ might reduce the enzyme inhibition. A similar relationship was observed between isovitexin and isoorientin $\left(\mathrm{IC}_{50}=61.2\right.$ vs. $1525.7 \mu \mathrm{M})$ (Chang et al. 2015).

\section{Flavonols}

In the study of Proença et al., the $\mathrm{IC}_{50}$ values of kaempferol, quercetin, and morin were found as 32, 15 , and $32 \mu \mathrm{M}$, respectively, suggesting that, $2^{\prime}, 4^{\prime}-$ dihydroxy and $3^{\prime}, 4^{\prime}$-dihydroxy substitutions increased the activity compared to single hydroxy substitution either at $3^{\prime}$ or $4^{\prime}$ position of the flavone ring B. However, galangin, which does not possess any substitution on ring $\mathrm{B}$, inhibited $\alpha$-glucosidase $21 \%$ at $200 \mu \mathrm{M}$ (Proença et al. 2017). In the study of Şöhretoğlu et al., the $\mathrm{IC}_{50}$ values of kaempferol and quercetin were 8.97 and 77.42 , respectively, and both compounds were determined as non-competitive inhibitors (Şöhretoğlu et al. 2018b). Moreover, Renda et al. found the $\mathrm{IC}_{50}$ values of kaempferol-3-O- $\alpha$ rhamnopyranoside and quercetin-3-O- $\alpha$-rhamnopyranoside as 29.92 and $74.51 \mu \mathrm{M}$, respectively (Renda et al. 2018). These two studies concluded that an extra hydroxyl group at $\mathrm{C}-3^{\prime}$ position of ring $\mathrm{B}$ decreased the inhibitory effect on the enzyme. Zeng et al. investigated $\alpha$-glucosidase inhibitory effects of morin and myricetin, which have very similar structures; the former has two hydroxyl groups at position $2^{\prime}$ and $4^{\prime}$, the latter has three hydroxyls at $3^{\prime}, 4^{\prime}$, and $5^{\prime}$ of ring $\mathrm{B}$, and the rest of their structures are the same. Their $\mathrm{IC}_{50}$ values were 4.48 and $2.25 \mu \mathrm{M}$, both substantially lower than that of acarbose, which was $304 \mu \mathrm{M}$. According to these results, increased number of hydroxyl groups on ring $B$ enhanced the $\alpha$-glucosidase inhibitory effect (Zeng et al. 2016).

\section{Flavanones}

Gou et al. investigated $\alpha$-glucosidase inhibitory potentials of two flavanones, liquiritigenin and liquiritin (liquiritigenin-4'-O-glucopyranoside), and found that both compounds were more potent than acarbose $\left(\mathrm{IC}_{50}=3.36,30.26\right.$ and $38.96 \mu \mathrm{g} / \mathrm{mL}$, respectively). The study suggested that the activity reduced by sugar substitution to $\mathrm{C}-4^{\prime}$ of ring B, i.e. $O$-glycosylation reduced the effect compared to the aglycon (Gou et al. 2016).

\section{Isoflavones}

In the study of Şöhretoğlu et al., the $\alpha$-glucosidase $\mathrm{IC}_{50}$ values of prunetin-5-O- $\beta$-glucopynoside, genistein-5-O- $\beta$-glucopynoside, and their aglycones, prunetin and genistein, were determined as 56.05, 43.24, 31.87 , and $1.47 \mu \mathrm{g} / \mathrm{mL}$, respectively, showing the importance of the free hydroxyl group at C-4' for isoflavones (Şöhretoğlu et al. 2017). In Fu et al.'s study, the $\alpha$-glucosidase $\mathrm{IC}_{50}$ values of alpinumisoflavone and $4^{\prime}$ - $O$-methylalpinumisoflavone were determined as 73.3 and $85.4 \mu \mathrm{M}$, indicating the lowering effect of $4^{\prime}$-methyl substitution on the activity of isoflavones (Fu et al. 2018). Similarly, methyl substitution to $4^{\prime}$-hydroxyl of 7-methyl,8geranyl-genistein weakened the inhibitory effects of these compounds on $\alpha$-glucosidase (Sun et al. 2015).

\section{Ring C}

\section{Flavonols}

In the study by Proença et al., the $\mathrm{IC}_{50}$ values of apigenin and luteolin were 82 and $46 \mu \mathrm{M}$. The $\mathrm{IC}_{50}$ of naringenin and eriodictyol could not be determined at concentrations up to $200 \mu \mathrm{M}$, but at this concentration they did inhibit the enzyme by $45 \%$ and $35 \%$, respectively. These results suggested that a double bond between C-2 and C-3 was crucial for $\alpha$-glucosidase inhibition (Proença et al. 2017). Many studies support that 3-hydroxy substitution enhances the $\alpha$ glucosidase potential of flavonoids (Zeng et al. 2016; Proença et al. 2017). However, replacement of this group with a chlorine had almost no effect on the activity (Proença et al. 2017). Li et al. compared the inhibitory potentials of quercetin, isoquercetin, and rutin and found their $\mathrm{IC}_{50}$ as $0.017,0.185$, and 
$0.196 \mu \mathrm{M}$, respectively. The $\mathrm{IC}_{50}$ of acarbose was $0.091 \mu \mathrm{M}$ in the same study. These results suggested that sugar substitution to C-3 hydroxyl reduced the inhibitory effect, however adding another sugar to the same position did not alter the effect of the monosugar derivative ( $\mathrm{Li}$ et al. 2009b). Meng et al. investigated $\alpha$-glucosidase inhibitory potentials of quercetin and myricetin. Both compounds inhibited the enzyme in a non-competitive manner with $\mathrm{IC}_{50}$ values of 32 and $3 \mu \mathrm{g} / \mathrm{ml}$, respectively. (Meng et al. 2016). The $\mathrm{IC}_{50}$ values of kaempferol, kaempferol-3-Omethylether, kaempferol-3-O-(3,4-di- $O$-acetyl- $a$-Lrhamnopyranoside), and kaempferol-3-O- $a$-Lrhamnopyranoside were found as $9.00,7.88,64.18$, and $81.16 \mu \mathrm{M}$, respectively, by Ajish et al. methyl substitution to the hydroxyl at C-3 increased the effect, while sugar substitution there decreased it. Also, the diacetylated rhamnopyranoside-substituted derivative exhibited higher effect than the non-acylated form (Ajish et al. 2015).

Şöhretoğlu et al. tested the $\alpha$-glycosidase inhibitory potential of kaempferol, quercetin, kaempferol 3-O- $\beta$ glucopyranoside, quercetin 3-O- $\beta$-glucopyranoside, quercetin 3-O- $\beta$-galactopyranoside, isorhamnetin 3-O- $\beta$-glucopyranoside, quercetin 3-O-(6" $-O$-galloyl)- $\beta$-galactopyranoside, quercetin $3-O-\left(3^{\prime \prime}-O\right.$-galloyl)- $\beta$-galactopyranoside, quercetin $3-O-\left(6^{\prime \prime}-O\right.$ galloyl)- $\beta$-glucopyranoside, kaempferol 3-O-vicianoside, and quercetin 3-O-vicianoside and found their $\mathrm{IC}_{50}$ values as 8.97, 77.42, > 100, > 100, $>100,>100,27.84,0.97,1.35,>100$, and $>100$ $\mu \mathrm{M}$, respectively. Some of these compounds were promising compared to acarbose $\left(\mathrm{IC}_{50}=50.58 \mu \mathrm{M}\right)$. The study pointed out reduced $\alpha$-glucosidase inhibitor potency due to glucosylation and galactosylation at $\mathrm{C}-3$ of ring $\mathrm{C}$. When the $\mathrm{IC}_{50}$ value of quercetin was compared to those of its galloylated sugar-substituted derivatives the substitution of ring $\mathrm{C}$ at $\mathrm{C}-3$ position with ( $O$-galloyl)glucopyranose or $(O$-galloyl)galactopyranose significantly boosted the inhibitory effect on the enzyme due to the galloyl moieties, which contain three hydroxyl groups. Moreover, substitution of the galactose unit at C-3" position by galloyl moiety increased the activity more compared to the substitution at C- 6 ". In this study, inhibition kinetics of some active compounds were also determined; quercetin 3-O-(6"-O-galloyl)- $\beta$-galactopyranoside was found competitive, kaempferol, quercetin, quercetin 3-O$\left(3^{\prime \prime}\right.$-O-galloyl)- $\beta$-galactopyranoside, and quercetin
3-O-(6"-O-galloyl)- $\beta$-glucopyranoside non-competitive inhibitors (Şöhretoğlu et al. 2018b). FloresBocanegra et al. also found that glycosylation of the hydroxyl at C-3 reduced the inhibitory effect of quercetin. However, benzoylation at C- $6^{\prime \prime}$ of the sugar moiety increased the inhibitory potential. Quercetin-3$O$-(6 $6^{\prime \prime}$-benzoyl)- $\beta$-galactoside and quercetin-3-O $\beta$ galactoside inhibited $\alpha$-glycosidase with $\mathrm{IC}_{50}$ of 0.03 and $0.40 \mathrm{mM}$, respectively. These two compounds also inhibited rat small intestinal $\alpha$-glycosidase with $\mathrm{IC}_{50}$ values of 0.43 and $1.98 \mathrm{mM}$, respectively. Their $S$. cerevisiae $\alpha$-glycosidase inhibitory potentials were better than acarbose but their rat small intestinal $\alpha$ glycosidase inhibitory potentials were not (FloresBocanegra et al. 2015). Overall, $O$-glycosylation reduced the inhibitory effect of flavonols.

\section{Flavanones}

According to the study by Proença et al. naringenin and eriodictyol at $200 \mu \mathrm{M}$ resulted in an $\alpha$-glucosidase inhibition of $45 \%$ and $35 \%$. Taxifolin was a slightly stronger inhibitor than them $\left(\mathrm{IC}_{50}=200 \mu \mathrm{M}\right)$ and acarbose $\left(\mathrm{IC}_{50}=607 \mu \mathrm{M}\right)$ in the same study. These results suggested that a hydroxy substitution to $\mathrm{C}-3$ of ring $\mathrm{C}$ enhanced the inhibitory potential (Proença et al. 2017).

Molecular modelling studies on $\alpha$-glucosidase inhibitor flavonoids

Most of the literature featuring molecular modelling of $\alpha$-glucosidase inhibition by flavonoids aim to predict binding affinities of the active compounds to the enzyme and identify key interactions of the highaffinity ligand-receptor complexes using molecular docking approach. Among the common issues in this pursuit is obtaining a structure model of the $\alpha$ glucosidase of the proper biological source used in the respective biological test, which usually was $S$. cerevisiae $\alpha$-glucosidase, because no experimental model for this enzyme has been available so far. The most preferred approach to this issue is creating a homology model of the enzyme. In almost all of the reported studies with homology modelling of $S$. cerevisiae $\alpha$-glucosidase, the crystal structure of preference for template was isomaltase of $S$. cerevisiae [PDB ID: 3A4A (Yamamoto et al. 2010) and 3AJ7 (Yamamoto et al. 2011)] obtained from the RCSB 
protein data bank (www.rcsb.org) (Berman et al. 2000). Isomaltase catalyzes hydrolysis of alpha 1-6 linkages in polysaccharides. Deposition of the crystal structure of this enzyme, which is highly homologous to $\alpha$-glucosidase ( $72 \%$ sequence identity), encouraged researchers for structure-based molecular modelling of $\alpha$-glucosidase inhibition. But there are exceptional studies such as that of Chang et al. (2015), in which Bacillus stearothermophilus $\alpha$-glucosidase was used for the in vitro studies; the researchers modelled the structure of this enzyme using human intestinal maltase-glucoamylase [PDB ID: 2QLY (Sim et al. 2008)] as template. Also, $\mathrm{Xu}$ (2010) used a crystal structure of oligo-1,6-glucosidase from Bacillus cereus [PDB ID: 1OUK (Watanabe et al. 1997)] as template to model $S$. cerevisiae $\alpha$-glucosidase; the two enzymes have $38 \%$ sequence identity. In some of the studies $\mathrm{X}$ ray structures were directly used for molecular docking studies, although the $\mathrm{X}$ ray structure of interest did not belong exclusively to the enzyme used in in vitro assays. For example, Wu et al. (2016) and Zhen et al. (2017) used crystal structures of isomaltase from $S$. cerevisiae although the inhibition assays were performed on $S$. cerevisiae $\alpha$-glucosidase (maltase). Flores-Bocanegra et al. (2015) tested a set flavonoids for their inhibitory effects against yeast and rat small intestinal $\alpha$-glucosidases and they performed molecular docking studies using homologous crystal structures such as yeast isomaltase [3A4A (Yamamoto et al. 2010)], human $N$-terminal sucrose-isomaltase [3LPP (Sim et al. 2010)], human $N$-terminal maltaseglucoamylase [2QMJ (Sim et al. 2008)], and human $C$ terminal maltase-glucoamylase [3TOP (Ren et al. 2011)]. Sun et al. (2015) used sugar beet $\alpha$-glucosidase [PDB ID: 3W37 (Tagami et al. 2013)] for molecular docking studies of their synthetic flavonoid derivatives, which has $41 \%$ sequence identity to $S$. cerevisiae $\alpha$-glucosidase, the enzyme used in the experimental studies. As a rule of thumb, the highest possible similarity between the structure of the enzyme used in vitro and the enzyme model used in silico is required for reliable in silico predictions.

Once the enzyme model is secured, the question where the inhibitors should bind on a protein arises. For crystal structures, catalytic sites are readily available at most times and for homology models the catalytic site can be inferred from the template. In the case of inhibitors that are not competitive the researchers applied various methods because this type of inhibitors may bind to allosteric site(s) as well. A commonly referred method in this case is blind docking, in which the whole surface of the protein is made available for binding, then the region where the highest number of docking poses cluster is identified. The blind docking approach was applied for flavonoids by Xu (2010), Kim et al. (2017), Zeng et al. (2016) and Zhen et al. 2017. This procedure is usually followed by a more exhaustive docking protocol at a limited search space to capture the best binding mode, which we see in the studies by Flores-Bocanegra et al. 2015 and Peng et al. 2016. Detecting cavities using special software is another way, especially, to handle ligands of different inhibition types as applied by Gong et al. (2017), Şöhretoğlu et al. (2017, 2018a, b), and Renda et al. (2018). In this procedure, the detected binding sites are scored and ranked for druggability. In some of the studies the catalytic site inferred from the template was used directly regardless of the inhibition type (Chang et al. 2015; Proença et al. 2017).

Most of these molecular modeling studies focused on natural flavonoids; among them, kaempferol, luteolin, quercetin, and myricetin were the most commonly modelled. In the study of Peng et al. kaempferol was reported to make only one hydrogen bond with Ser157 via 7-OH group. Kaempferol's lower potency against $\alpha$-glucosidase compared to myricetin and quercetin was attributed to having only one OH at ring B (Peng et al. 2016). In the study of Şöhretoğlu et al. (2018b) kaempferol and quercetin were found to be non-competitive inhibitors and docked to a number of predicted allosteric sites of the enzyme, however the compounds were able to form $\mathrm{H}$ bonds via different rings in different sites of the enzyme (Şöhretoğlu et al. 2018b). In the study of $\mathrm{Xu}$ et al. quercetin, luteolin, and myricetin were predicted to make H-bonds via the 7-OH substituent too, but with another residue, Glu304. In this study B ring of quercetin made two, luteolin and myricetin made three H-bonds with residues Asp68, Asp214, Thr215, Glu276, and Arg439 (Xu 2010). This ring was also found effective in $\mathrm{H}$-bond network in the study of Proença et al. forming three $\mathrm{H}$-bonds with residues Asp214 and Glu276 (Proença et al. 2017). So, the argument by Peng et al. seems to bear ground as myricetin and luteolin, reportedly, establish more effective $\mathrm{H}$-bond networks with yeast $\alpha$-glucosidase compared to kaempferol (Peng et al. 2016). These studies suggest four common residues for $\alpha$ - 
glucosidase inhibition by common flavonoids: Glu304 which accepts H-bond from the 7-hydroxy substituent; Asp214, Glu276, and Arg439, which engage in $\mathrm{H}$-bond interactions with the ring B hydroxyl groups. In general, these interactions and residues were offered as molecular determinants for their activity. Researchers also seem to have reached a consensus on the importance of some other moieties of the common flavonoid scaffold by studying various derivatives. For example, the importance of 3-hydroxy substitution was showed for the activity of myricetin by Xu et al., one kushenol derivative by Kim et al., and a number of flavones including quercetin by Proença et al. (Xu 2010, Kim et al. 2017, Proença et al. 2017). The carbonyl oxygen at the 4 th position plays a key role as H-bond acceptor according to many studies (Gong et al. 2017; Zhen et al. 2017; Şöhretoğlu et al. 2018b; Renda et al. 2018).

The effects of the sugar substitutions on the flavonoid scaffold is ambiguous. Still, some of the researchers cited above discussed these effects using molecular docking methods. For example, in the study of $\mathrm{Wu}$ et al. reducing the effect by increasing the number of sugar moieties attached to kaempferol or quercetin on their activity was attributed to the steric hindrance caused by these sugar moieties for effective binding interactions (Wu et al. 2016).

Scoring function is an important component of a docking methodology and docking scores usually provide insights into the efficacy of an inhibitor expressed as $\mathrm{IC}_{50}$ or $K_{\mathrm{i}}$ values. Therefore, strong correlation is aimed between docking scores and activity data. In most of the research manuscripts reviewed in this study, correlation between the predicted and measured affinities of the inhibitors were observed to some extent, possibly because the researchers in these studies preferred the structure model of the same enzyme used in the in vitro studies (Chang et al. 2015; Sun et al. 2015; Kim et al. 2017; Proença et al. 2017; Söhretoglu et al. 2017, 2018a, b, Renda et al. 2018). However, it is hard to talk about correlation in the case where only a limited number of ligands are tested. Enrichment studies in molecular modelling, in which the predictive capacity of a given model is tested, usually deal with thousands of ligands including actives and decoys. Perhaps the major pitfall of the molecular modelling parts of the reviewed studies is the lack of such comprehensive validation studies.

\section{Discussion}

$\alpha$-Glycosidase inhibitory potential of flavonoids has been widely studied and reported on; many potent derivatives were identified and SARs were established (Fig. 6). According to the general SARs of flavonoids regarding their $\alpha$-glycosidase inhibition 5-hydroxy substitution increased the effect but a sugar substitution to 5- or 7-hydroxyl group weakened it. Moreover, methyl substitution at the 7 th alone or at the 5 th and 7th positions together also decreased the inhibitory effect.

On the other hand, geranyl substitution at the 8th position of ring A enhanced inhibitory potential of flavonols and isoflavones. Geranylation enhanced the effect more than prenylation in flavonols. However, prenyl substitution at the 8th position increased the effect in flavonols, but decreased it in isoflavones dramatically. Further, replacement of 8-prenyl group by a lavandulyl group enhanced the inhibitory effect in flavonones. A double bond between C-2 and C-3 was found to be crucial for $\alpha$-glucosidase inhibition.

All the papers suggested that a free hydroxyl group at $\mathrm{C}-4^{\prime}$, which could make key interactions with the enzyme, is considered crucial. However, results on the effects of an additional hydroxyl group at C- $3^{\prime}$ were controversial, even in the same flavonoid subgroups. Some studies suggested that the hydroxyl group at C- $3^{\prime}$ in addition to $\mathrm{C}-4^{\prime}$ might reduce enzyme inhibition, while others suggested the opposite.

A hydroxyl group substitution at C-3 enhanced the activity, however replacing it with chlorine did not alter it. Furthermore, methyl substitution to the hydroxyl at C-3 increased, whereas a sugar substitution to this group decreased the effect.

A phenolic group substitution like gallic acid, coumaric acid, etc. at different positions of sugar units increased the inhibition. Hydroxy or methoxy substitutions on the phenyl group and geometric isomerism in the phenylpropenoyl moiety did not play an important role in enzyme inhibition. Further, 6"acetylation of glucose increased, but 3,4-di- $O$-acetylation of rhamnopyranoside decreased the effect. In general, $O$-glycosylation reduces bioactivity of flavonoids while $C$-glycosylation of flavonoids mostly enhances it (Xiao 2017). However, it seems both $O$ and $C$-glycosylation reduce $\alpha$-glycosidase inhibitory potential of flavonoids. 
Fig. 6 SAR of $\alpha$ glycosidase effects of flavonoids

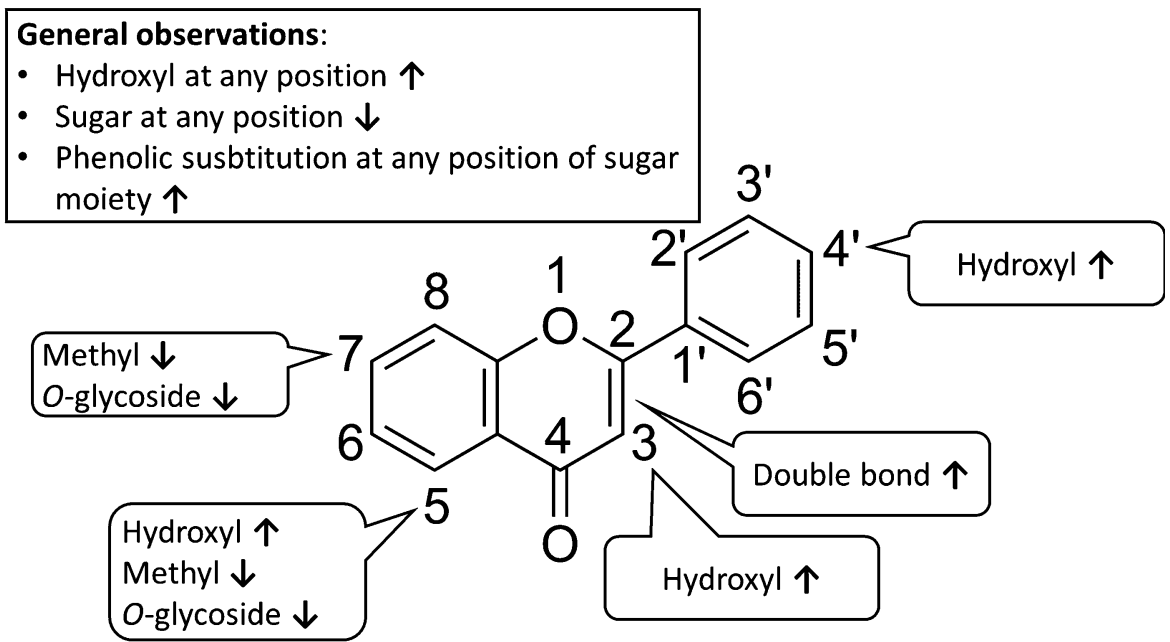

Molecular modelling was performed in some of these studies. Without proper experimental models for the enzymes used in these studies, especially for $S$. cerevisiae $\alpha$-glycosidase, the researchers took on different approaches, which yielded controversial results. Still, it was possible to observe consensus for certain SARs listed above. Hydroxyl groups at C-3 and $\mathrm{C}-7$ positions, the carbonyl oxygen at $\mathrm{C}-4$ position and hydroxyl groups of ring $\mathrm{B}$ were among the suggested key groups to enhance binding through H-bonds. As these studies focused on structure-based methods to understand the SARs of flavonoids one can easily notice the lack of ligand-based methods, which would probably provide valuable insights in the case where vast number of compounds with activity results are available but experimental enzyme models are not.

\section{Conclusions}

Flavonoids are promising $\alpha$-glycosidase inhibitors. The key observations of this review are given in Fig. 6. A double bond between $\mathrm{C}-2$ and $\mathrm{C}-3$ and a free hydroxyl group at $\mathrm{C}-4^{\prime}$ are crucial for $\alpha$-glucosidase inhibition. Hydroxylation of flavonoids generally increases the effect, though the effects of an additional hydroxyl group at $\mathrm{C}-3^{\prime}$ are contested. The addition of a sugar moiety to aglycon usually reduces the inhibitory effect, however further phenolic acid substitutions to these sugar units restore the inhibitory effect. Based on structure-based molecular modelling studies, it is possible to conclude that hydroxyl groups at C-3 and
C-7 positions, the carbonyl oxygen at C-4 position, and hydroxyl groups in ring $\mathrm{B}$ are among the suggested key groups to enhance binding to the enzyme through H-bonds.

\section{References}

Ajish KR, Antu KA, Riya MP, Preetharani MR, Raghu KG, Dhanya BP, Radhakrishnan KV (2015) Studies on $\alpha$-glucosidase, aldose reductase and glycation inhibitory properties of sesquiterpenes and flavonoids of Zingiber zerumbet Smith. Nat Prod Res 29:947-952

Berman HM, Westbrook J, Feng Z, Gilliland G, Bhat TN, Weissig H, Shindyalov IN, Bourne PE (2000) The Protein Data Bank. Nucleic Acids Res 28:235-242

Bischoff H (1995) The mechanism of alpha-glucosidase inhibition in the management of diabetes. Clin Invest Med 18(4):303-311

Chang C-C, Ho SL, Lee SS (2015) Acylated glucosylflavones as a-glucosidase inhibitors from Tinospora crispa leaf. Bioorg Med Chem 23:3388-3396

Chaudhury A, Duvoor C, Kraleti VSRDS et al (2017) Clinical review of antidiabetic drugs: implications for type 2 diabetes mellitus management. Front Endocrinol 8:12

Costa GM, Cárdenas PA, Gazola AC, Aragón DM, Castellanos L, Reginatto FH, Ramos FA, Schenkel EP (2015) Isolation of C-glycosylflavonoids with $\alpha$-glucosidase inhibitory activity from Passiflora bogotensis Benth by gradient highspeed counter-current chromatography. J Chromatogr B Analyt Technol Biomed Life Sci 990:104-110

Evans WC (2002) Trease and Evans pharmacognosy. Elsevier Ltd., China, p 246

Flores-Bocanegra L, Pérez-Vásquez A, Torres-Piedra M, Bye R, Linares E, Mata R (2015) $\alpha$-Glucosidase Inhibitors from Vauquelinia corymbosa. Molecules 20:15330-15342 
Fu G, Li W, Huang X, Zhang R, Tian K, Hou S, Li Y (2018) Antioxidant and alpha-glucosidase inhibitory activities of isoflavonoids from the rhizomes of Ficus tikoua Bur. Nat Prod Res 32:399-405

Gao H, Kawabata J (2004) Importance of the B ring and its substitution on the $\alpha$-glucosidase inhibitory activity of baicalein, 5,6,7-trihydroxyflavone. Biosci Biotechnol Biochem 68:1858-1864

Ghorbani A (2017) Mechanisms of antidiabetic effects of flavonoid rutin. Biomed Pharmacother 96:305-312

Gong Y, Qin X-Y, Zhai Y-Y, Hao H, Lee J, Park Y-D (2017) Inhibitory effect of hesperetin on $\alpha$-glucosidase: molecular dynamics simulation integrating inhibition kinetics. Int $\mathbf{J}$ Biol Macromol 101:32-39

Gou S-H, Liu J, He M, Qiang Y, Nia J-M (2016) Quantification and bio-assay of $\alpha$-glucosidase inhibitors from the roots of Glycyrrhiza uralensis Fisch. Nat Prod Res 30:2130-2134

International Diabetes Federation, Diabetes Atlas. 2017. www. idf.org/diabetesatlas Cited 10 Nov 2018

Jacques PF, Cassidy A, Rogers G, Peterson JJ, Meigs JB, Dwyer JT (2013) Higher dietary flavonol intake is associated with lower incidence of type 2 diabetes. J Nutr 143(9):1474-1480

Kim JH, Cho CW, Kim HY et al (2017) $\alpha$-Glucosidase inhibition by prenylated and lavandulyl compounds from Sophora flavescens roots and in silico analysis. Int J Biol Macromol 102:960-969

Krentz AJ, Sinclair AJ (2012) The evolution of glucose-lowering drugs for type 2 diabetes. In: Bagchi D, Nair S (eds) Nutritional and therapeutic interventions for diabetes and metabolic syndrome. Elsevier, Cambridge

Lebovitz H (1997) $\alpha$-glucosidase inhibitors. Endocrinol Metab Clin North Am 26:539-551

Li H, Song F, Xing J, Tsao R, Liu Z, Liu S (2009a) Screening and structural characterization of alpha-glucosidase inhibitors from hawthorn leaf flavonoids extract by ultrafiltration LC-DAD-MS(n) and SORI-CID FTICR MS. J Am Soc Mass Spectrom 20:1496-1503

Li YQ, Zhou FC, Gao F, Bian JS, Shan F (2009b) Comparative evaluation of quercetin, isoquercetin and rutin as inhibitors of alpha-glucosidase. J Agric Food Chem 57:11463-11468

Liu YJ, Zhan J, Liu XL, Wang Y, Ji J, He QQ (2014) Dietary flavonoids intake and risk of type 2 diabetes: a metaanalysis of prospective cohort studies. Clin Nutr 33(1):59-63

Meng Y, Su A, Yuan S, Zhao H, Tan S, Hu C, Deng H, Guo Y (2016) Evaluation of total flavonoids, myricetin, and quercetin from Hovenia dulcis Thunb. as inhibitors of $\alpha$ amylase and $\alpha$-glucosidase. Plant Foods Hum Nutr 71:444-449

Peng X, Zhang G, Liao Y, Gong D (2016) Inhibitory kinetics and mechanism of kaempferol on a-glucosidase. Food Chem 190:207-215

Pereira DF, Cazarolli LH, Lavado C, Mengatto V, Figueiredo MS, Guedes A, Pizzolatti MG, Silva FR (2011) Effects of flavonoids on a-glucosidase activity: potential targets for glucose homeostasis. Nutrition 11-12:1161-1167

Proença C, Freitas M, Ribeiro D (2017) $\alpha$-glucosidase inhibition by flavonoids: an in vitro and in silico structure-activity relationship study. J Enzyme Inhib Med Chem 32:1216-1228
Ren LM, Qin XH, Cao XF, Wang LL, Bai F, Bai G, She Y (2011) Structural insight into substrate specificity of human intestinal maltase-glucoamylase. Protein Cell 2:827-836

Renda G, Sari S, Barut B et al (2018) $\alpha$-Glucosidase inhibitory effects of polyphenols from Geranium asphodeloides: inhibition kinetics and mechanistic insights through in vitro and in silico studies. Bioorg Chem 81:545-552

Sim L, Quezada-Calvillo R, Sterchi EE, Nichols BL, Rose DR (2008) Human intestinal maltase-glucoamylase: crystal structure of the N-terminal catalytic subunit and basis of inhibition and substrate specificity. $\mathrm{J}$ Mol Biol 375:782-792

Sim L, Willemsma C, Mohan S, Naim HY, Pinto BM, Rose DR (2010) Structural basis for substrate selectivity in human maltase-glucoamylase and sucrase-isomaltase N-terminal domains. J Biol Chem 285:17763-17770

Şöhretoğlu D, Sari S, Barut B, Özel A (2017) $\alpha$-Glucosidase inhibitory effect of Potentilla astracanica and some isoflavones: inhibition kinetics and mechanistic insights through in vitro and in silico studies. Int J Biol Macromol 105:1062-1070

Şöhretoğlu D, Suat Sari S, Soral M, Barut B, Özel A, Liptaj T (2018a) Potential of Potentilla inclinata and its polyphenolic compounds in $\alpha$-glucosidase inhibition: kinetics and interaction mechanism merged with docking simulations. Int J Biol Macromol 108:81-87

Şöhretoğlu D, Sari S, Barut B, Özel A (2018b) Discovery of potent $\alpha$-glucosidase inhibitor flavonols: insights into mechanism of action through inhibition kinetics and docking simulations. Bioorg Chem 79:257-264

Sun H, Li Y, Zhang X et al (2015) Synthesis, $\alpha$-glucosidase inhibitory and molecular docking studies of prenylated and geranylated flavones, isoflavones and chalcones. Bioorg Med Chem Lett 25:4567-4571

Tadera K, Minami Y, Takamatsu K, Matsuoka T (2006) Inhibition of alpha-glucosidase and alpha-amylase by flavonoids. J Nutr Sci Vitaminol 52:149-153

Tagami T, Yamashita K, Okuyama M, Mori H, Yao M, Kimura A (2013) Molecular basis for the recognition of long-chain substrates by plant \& alpha-glucosidase. J Biol Chem 288:19296-19303

Teoh SL, Das S (2018) Phytochemicals and their effective role in the treatment of diabetes mellitus: a short review. Phytochem Rev 17:1111-1128

Watanabe K, Hata Y, Kizaki H, Katsube Y, Suzuki Y (1997) The refined crystal structure of Bacillus cereus oligo-1,6glucosidase at 2.0 A resolution: structural characterization of proline-substitution sites for protein thermostabilization. J Mol Biol 269:142-153

Wu B, Song H-P, Zhou X, Liu X-G, Gao W, Dong X, Li H-J, Li $P$, Yang H (2016) Screening of minor bioactive compounds from herbal medicines by in silico docking and the trace peak exposure methods. J Chromatogr A 1436:91-99

Xiao J (2017) Dietary flavonoid aglycones and their glycosides: which show better biological significance? Crit Rev Food Sci Nutr 57:1874-1905

Xiao J, Kai G, Yamamoto K, Chen X (2013) Advance in dietary polyphenols as $\alpha$-glucosidases inhibitors: a review on structure-activity relationship aspect. Crit Rev Food Sci Nutr 53:818-836 
$\mathrm{Xu} \mathrm{H}$ (2010) Inhibition kinetics of flavonoids on yeast $\alpha$-glucosidase merged with docking simulations. Protein Pept Lett 17:1270-1279

Xu H, Luo J, Huang J, Wen Q (2018) Flavonoids intake and risk of type 2 diabetes mellitus: a meta-analysis of prospective cohort studies. Medicine 97(19):e0686. https://doi.org/10. 1097/MD.0000000000010686

Yamamoto K, Miyake H, Kusunoki M, Osaki S (2010) Crystal structures of isomaltase from Saccharomyces cerevisiae and in complex with its competitive inhibitor maltose. FEBS J 277:4205-4214

Yamamoto K, Miyake H, Kusunoki M, Osaki S (2011) Steric hindrance by 2 amino acid residues determines the substrate specificity of isomaltase from Saccharomyces cerevisiae. J Biosci Bioeng 112:545-550

Yeon JY, Bae YJ, Kim EY, Lee EJ (2015) Association between flavonoid intake and diabetes risk among the Koreans. Clin
Chim Acta 439:225-230. https://doi.org/10.1016/j.cca. 2014.10.042

Zeng L, Zhang G, Lin S, Gong D (2016) Inhibitory mechanism of apigenin on $\alpha$-glucosidase and synergy analysis of flavonoids. J Agric Food Chem 64:6939-6949

Zhang YL, Luo JG, Wan CX, Zhou ZB, Kong LY (2015) Four new flavonoids with $\alpha$-glucosidase inhibitory activities from Morus alba var. tatarica. Chem Biodivers 12:1768-1776

Zhen J, Dai Y, Villani T, Giurleo D, Simon JE, Wu Q (2017) Synthesis of novel flavonoid alkaloids as $\alpha$-glucosidase inhibitors. Bioorg Med Chem 25:5355-5364

Publisher's Note Springer Nature remains neutral with regard to jurisdictional claims in published maps and institutional affiliations. 